\title{
Effects of Clonidine Premedication on Intraoperative Blood Loss in Patients With and Without Opium Addiction During Elective Femoral Fracture Surgeries
}

\author{
Davood Ommi ${ }^{1}$; Houman Teymourian ${ }^{1}$; Alireza Zali ${ }^{1}$; Farzad Ashrafi ${ }^{1}$; Morteza Jabbary \\ Moghaddam ${ }^{1}$; Alireza Mirkheshti ${ }^{1, *}$ \\ ${ }^{1}$ Functional Neurosurgery Research Center, Shahid Beheshti University of Medical Sciences, Tehran, Iran \\ ${ }^{*}$ Corresponding author: Alireza Mirkheshti, Functional Neurosurgery Research Center, Shahid Beheshti University of Medical Sciences, Tehran, Iran. Tel/Fax: $+98-2177567840$, \\ E-mail: drmirkheshti@gmail.com \\ Received: September 14, 2014; Revised: December 7, 2014; Accepted: January 27, 2015
}

\begin{abstract}
Background: Opium is an addictive agent and one of the most common narcotics With great challenges of intraoperative hemodynamic instabilities.

Objectives: The current study aimed to assess the effects of clonidine on intraoperative blood loss in patients with and without opium addiction in femoral fracture surgeries.

Patientsand Methods: In a randomized clinical trial,160 candidates for elective femoral fracture operationsunder general anesthesia were divided into four groups of 40 subjects: group 1 (placebo 1), subjects without addiction received placebo 90 minutes before the operation; group 2 (placebo 2), patients with opium addiction received placebo as group 1; group 3 (Clonidine 1), patients without addiction received clonidine 90 minutes before the operation and group 4 (Clonidine 2), patients with opium addiction received clonidine as premedication. Results: Intraoperative blood loss in clonidine recipient groups, patients with and without addiction, was less than that of the placebos (both P values < 0.01) and the difference magnitude was higher in patients with opium addiction

Conclusions: Premedication with clonidine to decrease intraoperative blood loss can be more effective in patients with opium addiction than the ones without addiction.
\end{abstract}

Keywords: Opium; Clonidine; Substance Abuse; Hemorrhage

\section{Background}

Despite efforts in health education, prevention and different detoxification or rehabilitative treatment approaches, abuse of illicit substances is escalated throughout the years. This is illustrated by the fact that in 2003 around 19.5 million Americans (8.2\% of the population) of 12 and older were current users of illicit drugs (1). Opium addiction is common in Iran and some other Asian countries $(2,3)$.

The increasing number of drug abusers causes several problems in the medical management of complications in such patients and health professionals have concerns in all fields of health.

Anesthetic management of addict patients is one of the main concerns, especially in major operations. Intra and post-operative bleeding in patients with opium addiction, is the main concern during emergency and elective surgeries. some reports indicate that the amount of bleeding during and after surgery was more in this group of patients than patients without opium addiction (4).

Because of the high risk of hemodynamic instability during anesthesia in addict patients, anesthetic manage- ment of these patients is one of the great challenges for anesthesiologists (5). Blood loss control is a main approach to have a stable hemodynamic, reduce blood transfusion and consequently prevent the risk of complications such as hemolytic and non-hemolytic reactions, acute lung injury, transmission of viral and bacterial infections, hypothermia and coagulation disorders (6).

In recent years clonidine, an imidazole compound, is successfully used as an adjuvant to induce controlled hypotension and intraoperative bleeding (7-15). Clonidine is an established antihypertensive agent that apparently acts mainly through central alpha 2 adrenoreceptor stimulation and diminishes sympathetic outflow. It is shown that clonidine has the anxiolytic (16), anti-nausea and vomiting (17) and anti-shivering effects (18) ; moreover, it has sedative and analgesic characters by decreasing stress-induced central noradrenergic hyperactivity. Clonidine reduces anesthetic requirements and attenuates reflex cardiovascular response to tracheal intubation (19-25). Clonidine reduces postoperative shivering and recovery time and intraoperative anesthetic con- 
Ommi D et al.

sumption in patients with and without opium addiction under surgery $(26,27)$.

Although there are several studies on the effect of clonidine on intra-operative bleeding during surgery in patients without addiction, there is no direct study on the effect of clonidine on blood loss during operation in patients with opium addiction and control of intra-operative blood loss in this group of patients remains as a main problem that anesthesiologists and surgeons face.

\section{Objectives}

The current randomized, double blind study aimed to investigate the effects of oral clonidine premedication on intra-operative bleeding in patients with and without opium addiction undergoing elective femoral fracture operations in supine position to reach a bloodless surgery field and prevent unstable hemodynamic state, which results life threatening complications in this group of patients.

\section{Patients and Methods}

After obtaining written informed consent from each patient and approval of the institutional review board, 160 candidates for elective femoral fracture surgeries (80 with and 80 without addiction) aged 18 - 65 years, with the American society of anesthesiologists (ASA) physical status I - II were selected for the current randomized clinical trial study (Figure 1). Each group of 80 patients was divided into two groups of 40 . Therefore, there were four stratified randomized groups (40 patients control-placebo ,40 patients control-clonidine, 40 patients addictedplacebo and 40 patients addicted-clonidine) and also four stratified randomization lists to each combination of gender-addiction (addict male, addict female, nonaddict male and non-addict female). All four groups were selected with the same gender frequency distribution: in each group there were 32 males and eight females. Stratified Permuted-block Randomization (with the length of four) was used to assign subjects to the treatment groups. The power of analysis was $90 \%$ and type I error of $\alpha=0.05$.

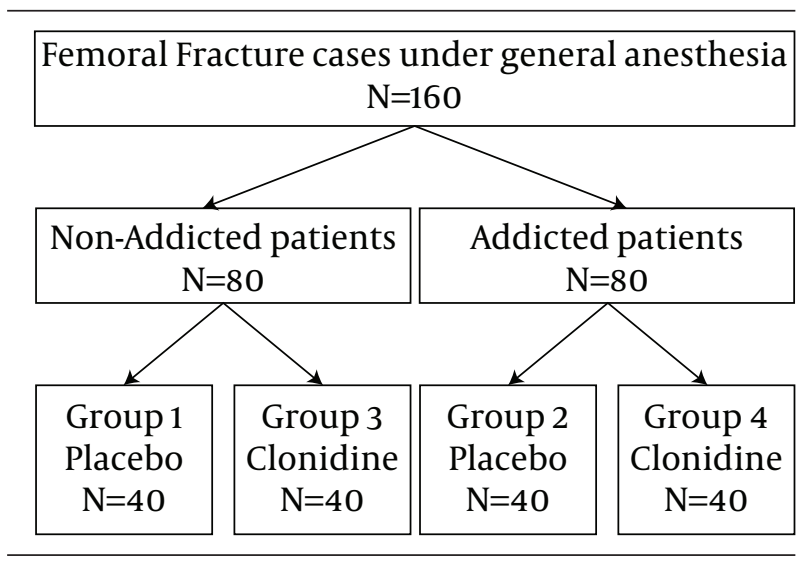

Figure 1. Consort Chart
The exclusion criteria were significant underlying diseases (hypertension, cardiac, hepatic or renal disease, coagulation defects, diabetes mellitus); multiple trauma and any other fractures, receiving beta receptor antagonists, autonomic nervous system active drugs, anticoagulant agents, long-acting corticosteroids, calcium channel blockers, digoxin, tricyclic antidepressants or clonidine two weeks before operation and the history of allergic reaction to any of the drugs used in the study. Operation time of more than 180 minutes was another exclusion criterion. If the patient consumed at least four grams of opium per day (natural or semi synthetic Alkaloids) orally or by inhalation for more than six months, in the subject was sent to the opium addict group. 80 addict and 80 nonaddict subjects with femur fractures were selected according to the subjects statement during the preoperative visit performed by one of the authors; then both groups were divided into two subgroups: 40 subjects in the clonidine and 40 in the placebo (sugar pill) groups, (according to the computer table of random numbers). All subjects, investigators, anesthesiologists, surgeons and nurses involved in the study were unaware of the assigned groups.

Before operation, routine laboratory tests as well as hemoglobin level, bleeding time, PT, PTT, and platelet count were checked for all patients in the four groups. The PT and PTT of each subject were divided by the control value of the laboratory and the results were recorded. Fasting time and pre-operation fluid therapy were similar in all four groups. Subjects in the clonidine groups (addict and non-addict) received oral clonidine $5 \mu \mathrm{g} / \mathrm{kg}$, 90 minutes before operation. This period ensures maximum plasma concentrations after oral ingestion of the drug. Control groups received placebo with similar color and shape to clonidine preparation.

The next steps in the operating room were the same for the four groups, performed by the same team (an anesthetist and a technician) who were unaware of the type of premedication or addiction. Subjects in the four groups received $7 \mathrm{~mL} / \mathrm{kg}$ of Ringer's solution before induction of anesthesia and were monitored by the same system for heart rate (HR) and SBP, and DBP and Electrocardiography; pulse oxymetry, end-tidal $\mathrm{CO}_{2}$, and urine output were also assessed. All subjects received fentanyl $2 \mu \mathrm{g} / \mathrm{kg}$ intravenously (IV) and midazolam $0.02 \mathrm{mg} / \mathrm{kg}$ IV as premedication 5 minutes before induction of anesthesia and induction of anesthesia was performed by thiopental $5 \mathrm{mg} / \mathrm{kg}$ and Atracurium $0.5 \mathrm{mg} / \mathrm{kg}$ IV. For the maintenance of anesthesia $\mathrm{O}_{2} / \mathrm{N}_{2} \mathrm{O}$ was used as $1 / 1$ liter and propofol by the infusion dosage of $100 \mu \mathrm{g} / \mathrm{kg} / \mathrm{minute}$ to preserve the value of Cerebral State Index (CSI) between 40 and 60. Systolic and diastolic blood pressure, heart rate, saturation of oxygen and cardiac rhythm were monitored and recorded 2 hours before surgery and at the time of anesthesia induction and each 10 minutes during the operation.

Intraoperative fluids for all patients included ringer lactate as maintenance fluid and normal saline for deficits and blood loss to a transfusion threshold of hemoglobin 
Ommi D et al.

$=10 \mathrm{~g} / \mathrm{dL}$. All operations were performed by the same surgery team and all surgeons and anesthesiologists were blinded to patient's groups during the operations. After the by acquiring the criteria for reversal of neuromuscular blockade, the patients' endotracheal tubes were extracted and by precise monitoring of hemodynamic and ventilation, they were transferred to postanesthesia care unit.

Intraoperative blood loss was estimated based on the volume of blood in the suction bottle and the weight of the bloody gauze pads. each pack of surgical pads were weighed before and after blood soaking and each milliliter of blood was considered nearly $1.06 \mathrm{mg}$; therefore, by weighing the pads and considering the volume of blood in the suction bottle the final blood loss could be estimated. The same anesthesiologist was responsible for all patients and he was unaware of the study details. The following data were recorded for each patient: age, gender, weight, and operation time. When patients acquired post anesthesia recovery score (modified Aldrete score) $>9$, the nurse of anesthesia let them leave the recovery room and be transferred to the orthopedic ward. The anesthesiologist who managed the subjects and recorded the volume of blood loss during surgery did not have any information about opium addiction and premedication of the subjects. All data were analyzed using SPSS (version 17.0; SPSS Inc. Chicago, IL). For statistical data analysis, student t test, Chi-square test and analysis of variance (ANOVA) with interaction were used. P values less than 0.05 were considered significant.

\section{Results}

As shown in Table 1, statistically, there were no significant differences between the subjects in the four groups and controls regarding age, gender, weight and duration of operation. Also there was no significant difference between coagulant tests (bleeding time, PT, PTT) and platelet count and the amount of hemoglobin between the four groups (Table 2).

Based on the mixed model, systolic blood pressure (SBP) in the placebo groups was significantly higher than that of the clonidine groups during the surgery $(\mathrm{P}<0.01)$ and addiction had no effect on clonidine action to control SBP ( $P=0.338)$, (Figure 2).

Also based on the mixed model, diastolic blood pressure (DBP) in the placebo groups was significantly higher than those of the clonidine groups $(\mathrm{P}<0.01)$ and again, addiction had no effect on clonidine action to control $\operatorname{DBP}(\mathrm{P}=0.136)$, (Figure 3$)$.

\begin{tabular}{|c|c|c|c|c|c|c|c|}
\hline \multirow[t]{2}{*}{ Characteristics of Subjects } & \multirow[t]{2}{*}{ Total } & \multicolumn{3}{|c|}{ Control } & \multicolumn{3}{|c|}{ Addict } \\
\hline & & Placebo & clonidine & $\mathbf{P}^{\mathbf{b}}$ & Placebo & Clonidine & $\mathbf{P}^{\mathbf{b}}$ \\
\hline Number of subjects & 160 & 40 & 40 & & 40 & 40 & \\
\hline \multirow[t]{3}{*}{ Age, $y$} & & & & 0.68 & & & 0.89 \\
\hline & $36.2 \pm 12.8$ & $32.9 \pm 14.2$ & $34.1 \pm 12.2$ & & $38.8 \pm 12.4$ & $39.1 \pm 11.3$ & \\
\hline & $34(18-64)$ & $27(18-64)$ & $33.5(18-64)$ & & $38(22-64)$ & $37(22-64)$ & \\
\hline Gender & & & & - & & & - \\
\hline Male & $128^{\mathrm{C}}$ & 32 & 32 & & 32 & 32 & \\
\hline Female & 32 & 8 & 8 & & 8 & 8 & \\
\hline \multirow[t]{3}{*}{ Weight, Kg } & & & & 0.28 & & & 0.06 \\
\hline & $71.6 \pm 11$ & $71.1 \pm 13.1$ & $73.9 \pm 10.2$ & & $68.4 \pm 9.9$ & $72.8 \pm 10.2$ & \\
\hline & $72(48-110)$ & $70(48-110)$ & $75.5(52-100)$ & & $68(51-90)$ & $73(55-100)$ & \\
\hline \multirow[t]{3}{*}{ Duration of operation, min } & & & & 0.69 & & & 0.51 \\
\hline & $110 \pm 28$ & $110 \pm 27$ & $108 \pm 23$ & & $114 \pm 30$ & $109 \pm 33$ & \\
\hline & $110(40-180)$ & $110(50-170)$ & $100(60-170)$ & & $120(40-180)$ & $110(40-180)$ & \\
\hline
\end{tabular}

\begin{tabular}{|c|c|c|c|c|c|c|c|}
\hline \multirow[t]{2}{*}{ Coagulant Tests } & \multirow[t]{2}{*}{ Total } & \multicolumn{3}{|c|}{ Control } & \multicolumn{3}{|c|}{ Addict } \\
\hline & & Placebo & clonidine & $\mathbf{P C}^{\mathrm{C}}$ & Placebo & Clonidine & $\mathbf{P C}^{\mathbf{C}}$ \\
\hline Number of subjects & 160 & 40 & 40 & & 40 & 40 & \\
\hline PT, s & $12.33 \pm 1.18$ & $12.3 \pm 1.2$ & $12.1 \pm 1.2$ & 0.83 & $12.6 \pm 1.1$ & $12.3 \pm 1.2$ & 0.61 \\
\hline PTT, s & $32.6 \pm 2.8$ & $33.4 \pm 2.8$ & $32.2 \pm 3.1$ & 0.51 & $32.1 \pm 2.4$ & $32.7 \pm 2.9$ & 0.72 \\
\hline BT, s & $104 \pm 51$ & $115 \pm 70$ & $94 \pm 37$ & 0.13 & $99 \pm 56$ & $108 \pm 41$ & 0.27 \\
\hline Platelet count, $1000 / \mathrm{mm}^{3}$ & $251 \pm 54$ & $242 \pm 52$ & $254 \pm 66$ & 0.62 & $259 \pm 44$ & $248 \pm 53$ & 0.51 \\
\hline Hemoglobin, mg/dL & $13.53 \pm 1.8$ & $13.3 \pm 1.8$ & $13.6 \pm 1.9$ & 0.23 & $14 \pm 1.6$ & $13.2 \pm 1.9$ & 0.13 \\
\hline
\end{tabular}

\footnotetext{
a Abbreviations: BT, Bleeding Time; PT, Prothrombin time; and PTT, partial Thromboplastin time.

b Results are presented as Mean \pm SD.

c Based on t-test.
} 
Ommi D et al.

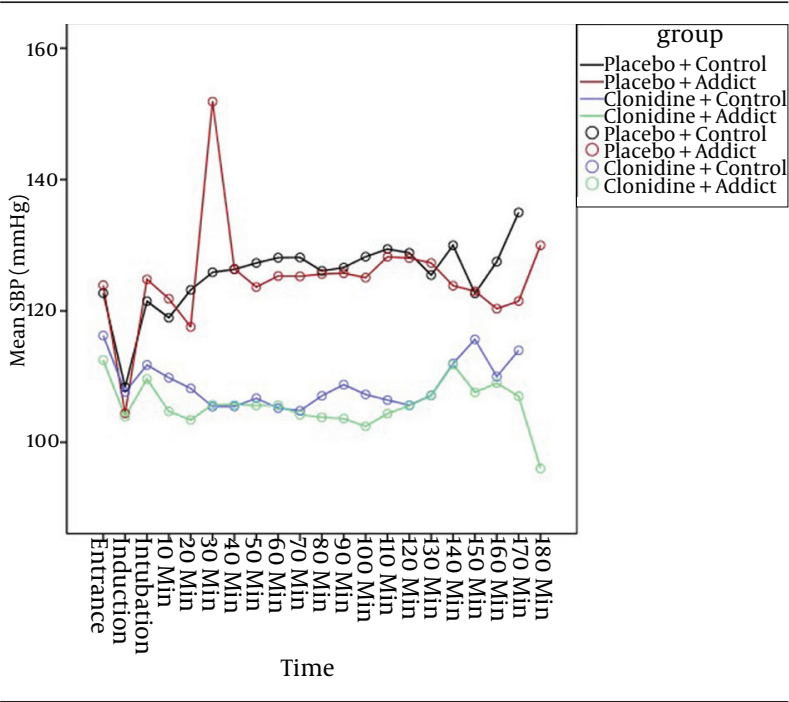

Figure 2. Mean Systolic Blood Pressure (mmHg)

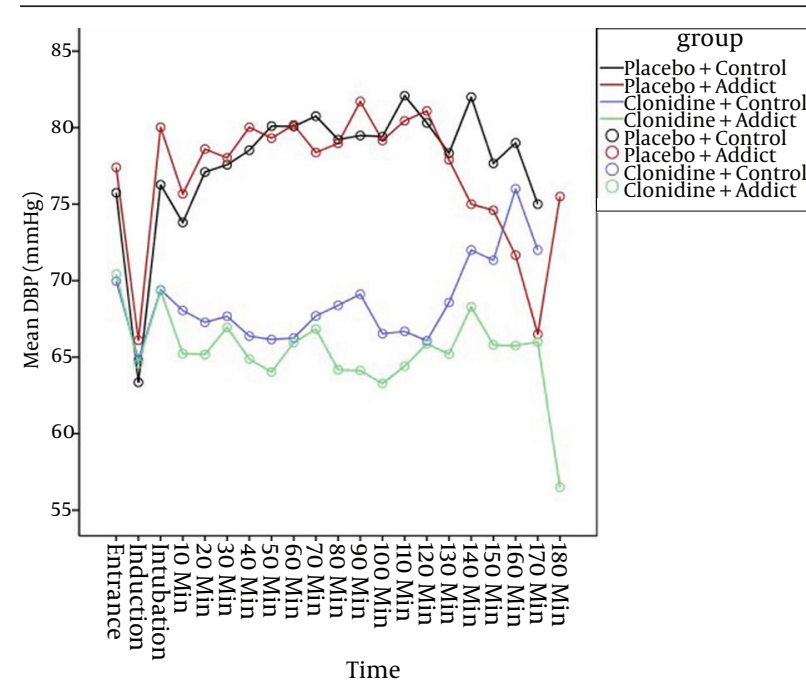

Figure 3. Mean Diastolic Blood Pressure (mmHg)

Table 3. Intraoperative Blood Loss

\begin{tabular}{|c|c|c|c|c|c|c|c|}
\hline \multirow[t]{2}{*}{ Variable } & \multirow[t]{2}{*}{ Total } & \multicolumn{3}{|c|}{ Placebo } & \multicolumn{3}{|c|}{ Clonidine } \\
\hline & & Control & Addict & $\mathbf{p}^{\mathbf{a}}$ & Control & Addict & $\mathbf{P}^{\mathbf{a}}$ \\
\hline Number of subjects & 160 & 40 & 40 & & 40 & 40 & \\
\hline Blood loss, mL & & & & 0.10 & & & $<0.01$ \\
\hline Mean $\pm S D$ & $288 \pm 184$ & $351 \pm 199$ & $375 \pm 246$ & & $222 \pm 71$ & $203 \pm 101$ & \\
\hline Median (Range) & $250(20-1400)$ & $310(100-1250)$ & $350(50-1400)$ & & $200(100-400)$ & $200(20-450)$ & \\
\hline
\end{tabular}

a Based on t-test.

Intra-operative blood loss in clonidine groups, subjects with and without opium addiction, was less than that of the placebo, and the difference was statistically significant (both $\mathrm{P}<0.01$ based on t-test). There was no significant difference regarding the intra operative blood loss volume between the two placebo groups $(\mathrm{P}=0.1)$ but it was significantly lower in clonidine-addict group in comparison with that of the clonidine-non addict subjects $(\mathrm{P}<0.01)$ (Table 3$)$.

\section{Discussion}

The current study showed that considering the nonsignificant difference in coagulation factors between all groups, clonidine decreased blood loss more significantly in the patients with opium addiction than the control ones during femur surgeries.

Blood loss in patients with addiction was evaluated in some studies $(4,28)$. Since the exact mechanism of excess bleeding in patients with addiction remained unclear and there were no evidence-based findings in the other studies on the effect of opium-addiction on surgical bleeding, it seems that further investigation is needed to find out more about the effect of opium addiction on bleeding during surgery.

Other findings of the current study showed that clonidine could control and decreased SBP and DBP in cloni- dine groups (addicted and non-addict) during surgery. In recent years, controlled hypotension is applied to reduce bleeding, as a technic in patients undergoing middle ear surgery, neurosurgery, orthopedic operations, head and neck and even in plastic surgery $(14,29)$. The use of drugs such as oral clonidine given before operation would be desirable to enhance the hypotensive action of inhalation agents, without disadvantages of intravenous vasodilators $(14,30)$. Controlled hypotension, applied by clonidine consumption in clonidine group, caused less intra-operative bleeding in the surgery.

Effect of clonidine on intra operative hemorrhage was shown in recent studies (30-33), but the novel finding of the current study was less blood loss in patients with opium addiction after clonidine consumption, in comparison with patients without addiction after clonidine consumption, while there was no significant difference in blood loss in patients without addiction after oral premedication with placebo.

The mentioned results showed that, clonidine has more effect on decreased blood loss in patients with opium addiction than non-addict ones. To the best of authors' knowledge, there is no study on the effect of oral clonidine on intra-operative bleeding in patients with opium addiction except the current survey. 
The study could not have equal numbers of different genders and the male ones were dominant in the study. Therefore, it seems that the results cannot be generalized regarding both genders. The other limitation was the lack of lab data on the level of opium in patients' serum or urine and the study relied on the subjects regarding the history of their addiction. It was due to an attempt to preserve patients' rights and authors did not intend to create any discomfort for Patients to have any addiction test.

In summary the current study showed that oral clonidine was an appropriate premedication to decrease blood loss, in patients without addiction and especially in opium addicted patients with opium addiction during orthopedic surgeries. Regarding the therapeutic effects of clonidine, clonidine is recommended as a premedication in patients with and without opium addiction, to reduce intra-operating blood loss and decrease adverse effects of hemodynamic instability.

\section{Acknowledgements}

The authors wish to thank all anesthesiology nurses and residents who helped them conduct the study.

\section{Authors' Contributions}

Davood Ommi: study concept and design; Houman Teymourian: acquisition of data; Alireza Zali: critical revision of the manuscript for important intellectual content; Farzad Ashrafi: administrative, technical, and material support; Morteza Jabbary Moghaddam: study supervision; Alireza Mirkheshti: drafting of the manuscript.

\section{References}

1. US Department of Health and Human Services. National Survey on Drug Use and Health.Washington DC: US Department of Health and Human Services; 2003.

2. Rajabizade G, Ramezani MA, Shakibi MR. Prevalence of Opium Addiction in Iranian Drivers 2001-2003. Journal of Medical Sciences(Faisalabad). 2004;4(3):210-3.

3. Karbakhsh M, Salehian Zandi N. Acute opiate overdose in Tehran: the forgotten role of opium. Addict Behav. 2007;32(9):1835-42.

4. Nemati MH, Astaneh B, Ardekani GS. Effects of opium addiction on bleeding after coronary artery bypass graft surgery: report from Iran. Gen Thorac Cardiovasc Surg. 2010;58(9):456-60.

5. Hernandez M, Birnbach DJ, Van Zundert AA. Anesthetic management of the illicit-substance-using patient. Curr Opin Anaesthesiol. 2005;18(3):315-24.

6. Fries D, Martini WZ. Role of fibrinogen in trauma-induced coagulopathy. Br JAnaesth. 2010;105(2):116-21.

7. Marchal JM, Gomez-Luque A, Martos-Crespo F, Sanchez De La Cuesta F, Martinez-Lopez MC, Delgado-Martinez AD. Clonidine decreases intraoperative bleeding in middle ear microsurgery. Acta Anaesthesiol Scand. 2001;45(5):627-33.

8. Hajymohammadi F, Farad F, Taheri A, Hoozan B. [Clonidine decreases intra operative bleeding in endoscopic surgery]. Tehran Univ Med J. 2002;60(5):378-82.

9. Jabalameli M, Hashemi SM, Soltani HA, Hashemi SJ. Oral clonidine premedication decreases intraoperative bleeding in patients undergoing endoscopic sinus surgery. Journal of Research in Medical Sciences. 2005;10(1):25-30.

10. Welfringer P, Manel J, Garric J. [Clonidine premedication and iso- flurane anesthesia to reduce bleeding in otologic surgery]. Ann Fr Anesth Reanim. 1992;11(2):125-31

11. Lee J, Lovell AT, Parry MG, Glaisyer HR, Bromley LM. I.v. clonidine: does it work as a hypotensive agent with inhalation anaesthesia? BrJ Anaesth. 1999;82(4):639-40.

12. Durmus M, But AK, Dogan Z, Yucel A, Miman MC, Ersoy MO. Effect of dexmedetomidine on bleeding during tympanoplasty or septorhinoplasty. Eur J Anaesthesiol. 2007;24(5):447-53.

13. Ayoglu H, Yapakci O, Ugur MB, Uzun L, Altunkaya H, Ozer Y, et al. Effectiveness of dexmedetomidine in reducing bleeding during septoplasty and tympanoplasty operations. J Clin Anesth. 2008;20(6):437-41.

14. Toivonen J, Kaukinen S. Clonidine premedication: a useful adjunct in producing deliberate hypotension. Acta Anaesthesio Scand.1990;34(8):653-7.

15. Degoute CS, Ray MJ, Manchon M, Dubreuil C, Banssillon V. Remifentanil and controlled hypotension; comparison with nitroprusside or esmolol during tympanoplasty. Can J Anaesth. 2001;48(1):20-7.

16. Striebel HW, Koenigs D, Heil T. [The role of clonidine in anesthesia]. Anaesthesist. 1993;42(3):131-41.

17. Handa F, Fujii Y. The efficacy of oral clonidine premedication in the prevention of postoperative vomiting in children following strabismus surgery. Paediatr Anaesth. 2001;11(1):71-4.

18. Mao CC, Tsou MY, Chia YY, Chow LH, Chan KH, Lee TY. Pre-anesthetic oral clonidine is effective to prevent post-spinal shivering. Acta Anaesthesiol Sin.1998;36(3):137-42.

19. Woodcock TE, Millard RK, Dixon J, Prys-Roberts C. Clonidine premedication for isoflurane-induced hypotension. Sympathoadrenal responses and a computer-controlled assessment of the vapour requirement. BrJAnaesth. 1988;60(4):11-394.

20. Flacke JW, Bloor BC, Flacke WE, Wong D, Dazza S, Stead SW, et al. Reduced narcotic requirement by clonidine with improved hemodynamic and adrenergic stability in patients undergoing coronary bypass surgery. Anesthesiology. 1987;67(1):11-9.

21. Engelman E, Lipszyc M, Gilbart E, Van der Linden P, Bellens B, Van Romphey A, et al. Effects of clonidine on anesthetic drug requirements and hemodynamic response during aortic surgery. Anesthesiology. 1989;71(2):178-87.

22. Maze M, Birch B, Vickery RG. Clonidine reduces halothane MAC in rats. Anesthesiology. 1987;67(5):868-9.

23. Kaukinen S, Pyykko K. The potentiation of halothane anaesthesia by clonidine. Acta Anaesthesiol Scand.1979;23(1):107-11.

24. Lyons FM, Bew S, Sheeran P, Hall GM. Effects of clonidine on the pituitary hormonal response to pelvic surgery. Br J Anaesth. 1997;78(2):134-7.

25. Ghignone M, Quintin L, Duke PC, Kehler CH, Calvillo O. Effects of clonidine on narcotic requirements and hemodynamic response during induction of fentanyl anesthesia and endotracheal intubation. Anesthesiology. 1986;64(1):36-42.

26. Moghadam MJ, Ommi D, Mirkheshti A, Shadnoush M, Dabbagh A. The effect of pretreatment with clonidine on propofol consumption in opium abuser and non-abuser patients undergoing elective leg surgery.J Res Med Sci. 2012;17(8):728-31.

27. Jabbary Moghaddam M, Ommi D, Mirkheshti A, Dabbagh A, Memary E, Sadeghi A, et al. Effects of clonidine premedication upon postoperative shivering and recovery time in patients with and without opium addiction after elective leg fracture surgeries. Anesth Pain Med. 2013;2(3):107-10.

28. Asgary S, Sarrafzadegan N, Naderi GA, Rozbehani R. Effect of opium addiction on new and traditional cardiovascular risk factors: do duration of addiction and route of administration matter? Lipids Health Dis. 2008;7:42.

29. Aken HV, Miller ED. Delibrate hypotension. In: Miller RD, Cucchiara RF, editors. Anesthesia. 5 ed. Philadelphia: cherchill livingstone; 2000. pp.1470-2.

30. Woodcock TE, Millard RK, Dixon J, Prys-Roberts C. Clonidine premedication for isoflurane-induced hypotension. Sympathoadrenal responses and a computer-controlled assessment of the vapour requirement. BrJAnaesth. 1988;60(4):388-94.

31. Boison-Bertrand D. [Reduction du saignement en microchirurgie otorhinologique]. Ann FrAnesth Re'anim. 1989;8:4A. 
32. Bertrand D, Boivin G, Manel J, Laxenaire MC. [Effects of isoflurane on bleeding in microsurgery of the middle ear]. Ann Fr Anesth Reanim. 1987;6(5):416-8.

33. Woodcock TE, Millard RK, Dixon J, Prys-Roberts C. Clonidine premedication for isoflurane-induced hypotension. Sympathoad- renal responses and a computer-controlled assessment of the vapour requirement. BrJ Anaesth. 1988;60(4):388-94.

34. Taghipour Anvari Z, Afshar-Fereydouniyan N, Imani F, Sakhaei M, Alijani B, Mohseni M. Effect of clonidine premedication on blood loss in spine surgery. Anesth Pain Med. 2012;1(4):252-6. 